\title{
Estimation of the Cellulose Microfibril Angle in Acacia mangium Wood Using Small-Angle X-Ray Scattering
}

\author{
Tamer A. Tabet (Corresponding author) \\ School of International Tropical Forestry, Universiti Malaysia Sabah \\ Locked Bag No. 2073, 88999, Kota Kinabalu, Sabah, Malaysia \\ Tel: 6-088-320000 Ext: 8593 E-mail: tamertbt@ums.edu.my \\ Fauziah Haji Abdul Aziz \\ School of Science and Technology, Universiti Malaysia Sabah \\ Locked Bag no. 2073, 88999, Kota Kinabalu, Sabah, Malaysia \\ Tel: 6-088-320000 Ext: 5792 E-mail: afauziah@ums.edu.my
}

\begin{abstract}
The term microfibril angle, MFA in wood science refers to the angle between the direction of the helical windings of cellulose microfibrils in the secondary cell wall, $\mathrm{S}_{2}$ layer of fibres and the long axis of the cell wall. A method is presented for the measurement, using small-angle X-ray scattering (SAXS), of the microfibril angle, (MFA) and the associated standard deviation for the cellulose microfibrils in the $\mathrm{S}_{2}$ layer of the cell walls of Acacia mangium wood. The length and orientation of the microfibrils of the cell walls in the irradiated volume of the thin samples are measured using SAXS and scanning electron microscope, (SEM). The undetermined parameters in the analysis are the MFA, $(M)$ and the standard deviation $\left(\sigma_{\Phi}\right)$ of the intensity distribution arising from the wandering of the fibril orientation about the mean value. Nine separate pairs of values are determined for nine different values of the angle of the incidence of the X-ray beam relative to the normal to the radial direction in the sample. The results show good agreement. The curve distribution of scattered intensity for the real cell wall structure is compared with that calculated with that assembly of rectangular cells with the same ratio of transverse to radial cell wall length. It is demonstrated that for $\beta=45^{\circ}$ (where $\beta$ is the angle between the plane face of the wood samples and the radial direction) the peaks in the curve intensity distribution for the real and the rectangular cells coincide. If this peak position is $\Phi_{45}$, Then the MFA can be determined from the relation $M=\tan ^{-1}\left(\tan \Phi_{45} / \cos 45^{\circ}\right)$, which is precise for rectangular cells.
\end{abstract}

Keywords: Small-Angle X-Ray Scattering, SAXS, Microfibril angle, MFA, Fibre length, $L$

\section{Introduction}

Acacia mangium represents one of the major fast growing species used in plantation programmes in Malaysia and Asia. The species was introduced into Malaysia in 1966 as an exotic species and has become firmly established as the principle species used for timber production and an important source of fibre for bulb industry. There important as a plantation species can be attributed to rapid growth rather than good wood quality and tolerance about 30 meters to a range of soil.

The microfibril angle (MFA) of the $\mathrm{S}_{2}$ layer in the fibres cell wall is known to be one of the main determinants of the mechanical properties of the solid wood (Cave and walker 1994; Evans Ilic 2001), shrinkage anisotropy (Cave 1972). Microfibril angle plays a crucial role in determining the thermal and dynamic-mechanical properties such as storage modulus, loss modulus and glass transition of Acacia mangium wood (Tamer et al., 2009). Extensive work has been done to evaluate the relationship between MFA and strength properties of individual fibres (Rayirath et al., 2008)). These studies have shown that fibres with smaller MFA were characterized by higher tensile and tear properties, as well as high modulus of elasticity.

Several methods for determining MFA have been developed over the years (Cave 1989). Mostly all of them are time-consuming and not suitable for large scale utilisation. However recently, an X-Ray diffraction technique developed for silviScan-2 (Evans, 1999) and (Laurence et al., 2005) have successfully simplified the assessment of MFA. 
Measurements of MFA using SAXS on single wood fibres have been pioneered by Meylan and Probine (1998). Additionally, Reiterer et al., (1998) also mention the use of the SAXS to investigate the spiral in the wood cell wall, but their primary assumption in the analysis is that the wood cell walls are square. It is necessary to take into account the detailed cell structure in order to interpret diffraction and scattering data (Entwistle, and Navaranjan, 2002). This involved using quantitative image analysis or SEM to measure the length and the orientation of the microfibrils in the irradiated volume of the thin samples. From the data the angle of the peak scattering intensity $\Phi_{\mathrm{p}}$ was calculated for a sample irradiated in a direction of $45^{\circ}$ to the radial and transverse direction. It was thereby demonstrated that the MFA could be calculated from the formula (1).

$$
M=\tan ^{-1}\left(\tan \Phi_{p} / \cos 45^{\circ}\right)
$$

Where: $M$ the MFA in $\mathrm{S}_{2}$ layer, with an error about $1^{\circ}$. The relation is exact for rectangular cells (Entwistle and Navaranjan, 2002).

In the present paper we describe a more detailed investigation based on the same approach. We first determine using SAXS and SEM the length and orientation of the cell walls in the irradiated volume of the sample. The two significant parameters in the analysis are the MFA, $M$ and the standard deviation of the scattering $\sigma_{\Phi}$ caused by the orientation spread of the constituent fibrils. The small-angle scattered intensity is measured using small-wide angle x-ray scattering machine and the MFA was calculated accordance with (Cave, 1966).

\section{Materials and Methods}

Wood samples of 10 year-old Acacia mangium plantation trees were obtained from two compartments with different site located in Sabah, Malaysia. Two trees from each compartment were selected providing a total 4 trees for this study. Two discs of $40 \mathrm{~mm}$ were taken at breast height of the stem for each tree (at approximately $1.25 \mathrm{~m}$ height from the ground level). In total, eight knot-free discs were labelled and stored in plastic bags for further sample preparation.

\subsection{Sample Preparation}

Samples of 9 different orientations were cut as indicated in Figure 1. The angle $\beta$ shown is between the wider face of the sample and the radial direction. The samples irradiated with the X-ray beam has a circular cross-section of $0.6 \mathrm{~mm}$ in diameter directed normal to the normal that face. $\beta$ is the angle between the normal to the radial plane and the direction of the X-ray beam. The various cell-wall orientations were obtained by cutting specimens as shown in Figure 2, so that the scattered radiation would pass through the same length of specimen material in all cases. Without any further treatment, it is encapsulated in plastic foil to keep them from drying and shrinking in the vacuum chamber of the x-ray equipment. A SAXS device (HMBG-SWAX, SAXS PW 3830 $\mathrm{X}$-ray generator) was used to determine the MFA in each of the eight investigated trees.

The experimental set-up consisted of $40 \mathrm{kV}$ and $20 \mathrm{~mA}$. The incoming x-ray beam had a circular cross-section of $0.6 \mathrm{~mm}$ in diameter. The information on the beam position were obtained by rapid scanning of the whole sample and the total intensity at each position been recorded.

Since the total scattering intensity can be considered roughly proportional to the amount of scattering material irradiated by the beam, it can be used for determining the beam position on samples that are inhomogeneous in density. In the case of wood, the difference in density between the cellulose fibrils and the surrounding hemicellulose-lignin matrix, allows one to image the fibre orientation in the cell wall layers in the wood section. Next, several points of interests were chosen to investigate the nanostructure of the wood cell wall. Extensive scans over wood slices were carried out. The MFA was determined from the scattering pattern for each measurement point and correlated with the age of tree and the distance from pith towards bark. All samples were characterized by taking SEM and polarization microscope. These images were taken from cross-sections cut from the same block as the sample used for SAXS.

\subsubsection{Theory}

The equations used to calculate the scattered intensity and MFA were derived by Entwistle \& Navaranjan (2002). In Figure 4, $z$ is the direction of the cell axis, $\mathrm{y}$ is the radial direction and $\mathrm{x}$ is the transverse direction. A cell wall was shown with two sets of $\mathrm{S}_{2}$ microfibrils $\mathrm{f}_{1}$ and $\mathrm{f}_{2}$ lying at the microfibril angle, $M$ to the cell axis direction $z$. The incident $\mathrm{X}$-ray beam is directed along $\mathrm{x}$ axis. The normal to the cell wall lies at an angle $\alpha$ to the direction of the X-ray beam. The calculated azimuth angle $\Phi_{1}$ for the scattered intensity from the fibril $\mathrm{f}_{1}$ is given by

$$
\tan \Phi_{1}=-\cos \alpha \tan M
$$


The corresponding calculated azimuth angle $\Phi_{2}$ for scattering from $\mathrm{f}_{2}$ is given by:

$$
\tan \Phi_{2}=-\cos (\alpha+\pi) \tan M=\cos \alpha \tan M
$$

and so $\Phi_{1}=-\Phi_{2}$ and the scattered intensity is symmetrical about $\Phi=0^{\circ}$.

A sample is cut so that the radial direction is at an angle $\beta$ to the front face of the wood section (Figure 5). The $\mathrm{X}$-rays are directed normal to the front face. For a cell wall lying at an angle $\theta$ to the radial direction, the value of $\alpha$ is:

$$
\alpha=(\beta+\theta)
$$

and thus the azimuthal angle for scattering from $\mathrm{f}_{1}$ fibrils in the cell wall is given from equation (5) by:

$$
\tan \Phi_{1}=-\cos (\beta+\theta) \tan M
$$

and for scattering from the $\mathrm{f}_{2}$ microfibrils, $\Phi_{2}$ is given from equation (6) by

$$
\tan \Phi_{2}=\cos (\beta+\theta) \tan M
$$

Measurement on the nine samples used, have angles:

$\beta=0,10,20,30,35,40,45,50$ and $90^{\circ}$.

The two parameters MFA denoted as $M$ and standard deviation $\sigma$ are determined by plotting the intensity distribution, I against scattering factor $q$.

\section{Results}

Figure 7 presents the determination of MFA by plotting intensity $I$ against the azimuthal variation of scattered intensity. The azimuthal angle $\Phi$ ranging from $-90^{\circ}$ to $90^{\circ}$; outside this range the scattered intensity is very small. Table 1 presents the estimated values for MFA and the orientation angle of the grain, $\beta$. It is shown that there is reasonable consistency between the values derived from the nine samples. It is observed that the lower values of $\beta$ give lower values of MFA. The critical values of $\beta$ lies at the higher flanks of the intensity distributions. This mean that, for values of $\beta$ less than $45^{\circ}$, the values of MFA are increased as the grain angle increased. For the $\beta$ greater than $45^{\circ}$, the data from Table 1 indicate that the value of MFA is slightly less than that estimated at value less than $45^{\circ}$. Figure 7 show a typical intensity distribution for $\beta=45^{\circ}$ versus the azimuthal angle $\Phi$. The higher peak arises from the $S_{2}$ layer and the lower peak is generated by $S_{1}$ and $S_{3}$ microfibrils. Table 1 indicate that the possible the value of estimated MFA using SAXS technique is slightly less than that for the grain orientation, $\beta$. In Figure 7, $\sigma_{\Phi}$ is the half-width of the peak. The width $T$ has been shown to be correlated to the MFA (Bergander, et al., 2002). The " $T$ " parameter was developed for wide-angle diffraction data but here no reason in principle why it should not be used for SAXS intensity distribution (Bonham \& Barnett, 2001). Here the MFA values were estimated from the Barnett et al., (2004) equation as following:

$$
\begin{gathered}
M F A=0.6 T \\
T=M F A+2 \sigma_{\Phi}
\end{gathered}
$$

Where $\sigma_{\Phi}$ is the half-width of the peak.

\subsection{The Comparison between Measured Value of MFA for Real cell Wall and the Rectangular Cell Wall}

It was found that the measured MFA of the intensity distributions for the real cell wall of Acacia mangium used and the calculated rectangular structure cell wall in a direction at $\beta=45^{\circ}$ were in agreement. The intensity for $\beta$ $=45^{\circ}$ was plotted in Figure 7. The peak intensity was found at $\Phi_{45}=24^{\circ}$. The relation between this azimuthal angle and MFA for the perfect rectangular cells is given by Bonham \& Barnett (2001):

$$
\begin{gathered}
M F A=\tan ^{-1}\left(\tan \phi_{45} / \cos 45\right) \\
M F A=\tan ^{-1}(\tan 24.0 / 0.707) \\
M F A=\tan ^{-1}(0.445 / 0.707) \\
M F A=32.16^{\circ}
\end{gathered}
$$

The measured value of the real cell of Acacia mangium MFA $=29.4^{\circ}$, so the use of the relation for rectangular cells to interpret the measured data gives a good estimate of MFA. Figure 6 shows a SEM micrograph for the real cell wall used for the MFA estimation. Figure 8, shows the variation of estimated MFA with the angle $\beta$.

The strong relationship between MFA and the distance from pith to bark which has previously been shown using XRD method (Tamer \& Aziz, 2009) was confirmed that the regression analysis showed that a straight line fit the 
data very well. It was found that $95.97 \%$ of the variation of MFA can be attributed to the distance from pith to bark of wood model 10-year-old (Figure 9). Based on the results as shown in Figure 9 for Acacia mangium wood model of 10-year-old. This technique can be used to deduce the MFA for other tree samples of different ages. This observation support those of Bonham and Barnett (2001) who found that MFA in Betula pendula Roth varied from $10^{\circ}$ to $18^{\circ}$ with the distance from pith towards bark. As can be seen, there is noticeable results between the values of MFA as obtained through XRD and SAXS (Tamer et. al, 2008) methods with the distance from pith to bark. It is clear that the lower values of MFA obtained through SAXS for the wood samples compliment with the method used by XRD method. The error bars for MFA in Figure 8 and 9 were estimated to represent the uncertainties in MFA as a minus and plus error bars.

\section{Discussion and Conclusion}

This study for the measurement of MFA using SAXS in the $\mathrm{S}_{2}$ layer of the real cell walls of Acacia mangium wood used a 10.0 year old tree. The results show that MFA varied from $18.0^{\circ}$ at distance $10.0 \mathrm{~mm}$ from the pith center and finally at $30.6^{\circ}$ at $90.0 \mathrm{~mm}$ from the pith (Table 1). The highest MFA has been found near the outer bark at the breast height of the tree. This result supports the statement made by Lichtenegger et al., (1999) who found that MFA in hardwoods were lower than in softwoods. An example shown is in the hardwood tree of Norway spruce where MFA after the $7^{\text {th }}$ year ring varies between $6^{\circ}$ to $10^{\circ}$ (Andersson, 2006). Acacia mangium wood as a hardwood contains vessel elements in which the MFA can be higher. On this basis, The MFA values measured in this wood model is reasonable. The presence of vessels, especially in high abundance might be expected to increase $\mathrm{x}$-ray diffractometric estimates MFA for hardwoods in comparison to softwoods (Bonham and Barnett, 2001). Removal of the contribution of vessels from the average values found in hardwoods might therefore result in an even lower value of MFA for the fibres (Evans, 1999).

However, the contributions arising from the vessels walls in Acacia mangium wood and from the $\mathrm{S}_{1}$ and $\mathrm{S}_{3}$ fibre wall layers add mainly to the back ground and not to the peaks used to calculate the $\mathrm{S}_{2}$ MFAs (Evans, 1999). Bonham and Barnett (2001) reported that tension wood or gelatinous fibres (hardwoods) generally have an MFA of between $0^{\circ}$ to $30^{\circ}$, while softwood have a large MFA, greater than $30^{\circ}$. MFA can be used a good indicator to estimate of hardwoods and softwood based on its value. Wood containing fibres with an MFA of $30^{\circ}$ or below have been termed hardwoods wood, while wood containing fibres with MFA of $30^{\circ}$ or more have been termed softwoods (Bonham and Barnett, 2001). This can be proved again in Acacia mangium wood from Sabah where the mean value of MFA from pith to bark was found to be $24.2^{\circ}$ in the wood disc of 10-year-old. In another study, it was shown that Acacia mangium wood from Sabah of 5 and 9-year-old where MFA ranges from $0.32^{\circ}$ to $27.36^{\circ}$ for wood disc of 5-year-old and from $0.46^{\circ}$ to $14.44^{\circ}$ for 9-year-old (Tamer \& Aziz, 2009).

\section{Acknowledgment}

We would like to thank fully to the Universiti Malaysia Sabah, and also to the Universiti Kebangsaan Malaysia for their professional assistance.

\section{References}

Anderson, A. D. (2006). A Study of the Nanostructure of the Cell Wall of the Tracheids of Conifer Xylem by X-Ray Scattering. University of Helsinki, Report Series in Physics. HU-P-D 135: 18-25.

Barnett, J.R., \& Vectoria A. Bonham. (2004). Cellulose microfibril Angle in the cell-wall of the Wood Fibre. Biological Reviews, 79, 461-472.

Bergander, A. J., Brandstrom, J., Daniel, G., \& Salmen L. (2002). Fibril Angle Variability in Earlywood of Norway spruce Using Soft rot Cavities and Polarisation Confocal Microscopy. Ournal of Wood Science, 48, 255-263.

Bonham, V.A., \& Barnett, J.R. (2001). Fibre Length and Microfibril Angle in Silver Brich (Betula Pendula Roth). Holzforschung, 55: 159-162.

Cave, I.D. (1989). Theory of X-Ray Measurement of Microfibril Angle in Wood. Journal of Wood Science and Technology, 11, 52- 60

Cave, I.D. (1966). X-ray measurement of microfibril angle. Journal of Forest Product, 44: 37 - 43.

Cave, I.D., \& Walker, J.F.C. (1994). Stiffness of Wood in Farown Plantation Softwood: The Influence of Microfibril angle. Forest Product Journal, 44, 69-78.

Entwistle, K.M., Eichhorn, S.J., \& Navaranjan, N. (2005). The derivation of Cellulose Microfibril angle by Small-Angle X-ray scattering from Structurally Characterized Softwood Cell-Wall Population. Journal of Applied Crystallography, 38, 505-511. 
Evans, R., Hughes, M. \& Menz, D. (1999). Microfibril Angle Variation by Scanning X-Ray Diffractometry. Appita Journal, 52, 363-367.

Lichtenegger, H., Reiterer, A., Stanzl-Tschegg, S.E. \& Fratzl, P. (2000). Variation of Cellulose Microfibril Angles in Softwoods and hardwoods: A Possible Strategy of Mechanical Optimization. Journal of Structural Biology, 128, 257-269.

Tamer, A., Fauziah A., \& Shahidan, R. (2008). A study of Fracture Surface of Fibres in Acacia mangium Wood Using Small-Angle X-Ray Scattering and Scanning Electron Microscope. Jurnal Fizik Malaysia, Vol. 29, No. $1 \& 2-35-40$.

Tamer, A. \& Fauziah, A. (2009). The Influence of Microfibril Angle on the Thermal and Dynamic-Mechanical Properties of Acacia mangium Wood. Jurnal of Nuclear and Related Technniques. Vol. 29, No. 1\&2-35-40.

Rayirath, P., Stavros, Avramidis., \& Shawn, D. (2008). The Effect of Wood Drying on the Crystallinity and Microfibril angle in Black Spruce (Picea mariana). Journal of Wood Chemistry and Technology, 28, pp. 167-179.

Reiterer, A. Jakob, H. F., Stanzl, S. E., \& Fratzl P. (1998). Spiral Angle of Elementary Cellulose Fibrils in Cell Walls of Picea abies Determined by Small-Angle X-Ray Scattering. Wood Science and Technol, 34, 335-345.

Laurence, R., Schimleck, Robert Evans \& Alexander Clark III. (2005). Estimation of Microfibril Angle and Stiffness by Near Infrared Spectroscopy Using Sample Sets Having Limited Wood Density Variation. [Online] Available: http:bio/kuleuven.be/sys//iawa/IAWA\%20J\%20pdf's/260.no.2.2005/175 -18 7.pdf. (May 30, 2010)

Table 1. Estimated MFA and the standard deviation $\sigma_{\Phi}$ for each value of $\beta$

\begin{tabular}{|c|c|c|c|c|}
\hline Sample No. & Distance from pith $(\mathbf{m m})$ & $\boldsymbol{\beta}\left(^{\circ}\right) \pm \mathbf{0 . 5}$ & $\begin{array}{c}{ }^{\circ} \\
\text { MFA }\left(^{\circ}\right)\end{array}$ & $\boldsymbol{\sigma}_{\boldsymbol{\Phi}}$ \\
\hline 1 & 10 & 0 & 18.0 & 6.0 \\
\hline 2 & 20 & 10.0 & 19.8 & 6.6 \\
\hline 3 & 30 & 20.0 & 19.2 & 6.4 \\
\hline 4 & 40 & 30.0 & 22.2 & 7.4 \\
\hline 5 & 50 & 35.0 & 24.0 & 8.0 \\
\hline 6 & 60 & 40.0 & 25.8 & 8.6 \\
\hline 7 & 70 & 45.0 & 29.4 & 9.8 \\
\hline 8 & 80 & 50.0 & 28.8 & 9.6 \\
\hline 9 & 90 & 90.0 & 30.6 & 10.2 \\
\hline
\end{tabular}



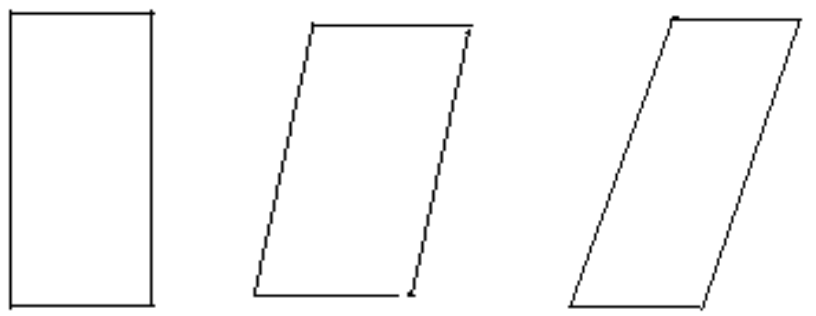

$\beta=0^{\circ} \quad \beta=10^{\circ}$

$\beta=20^{\circ}$

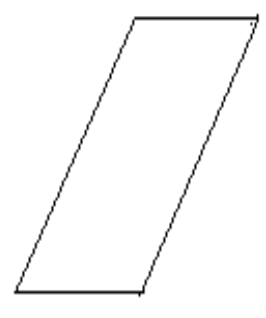

$\beta=30^{\circ}$

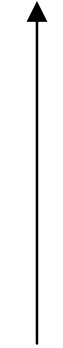

Radial direction

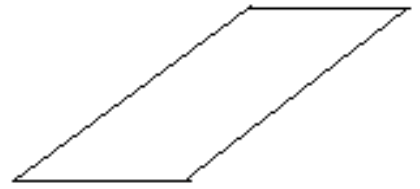

$\beta=50^{\circ}$
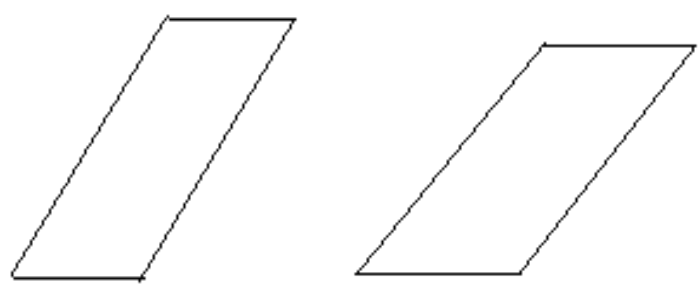

$\beta=35^{\circ}$

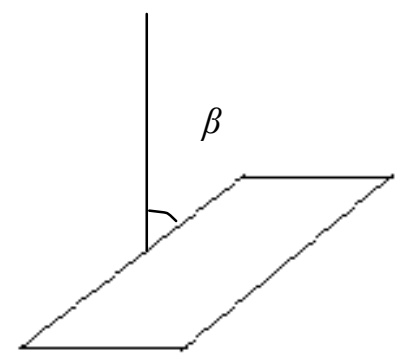

$\beta=45^{\circ}$

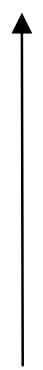

$\beta=90^{\circ}$

Radial direction

Wood section

Figure 1. Diagram showing the orientation of the cross-section of the Acacia mangium samples that cut from the wood disc. The vertical arrow is the radial direction, and $\beta$ is the angle between the radial direction and the irradiated face of the samples. Drawing not to scale 


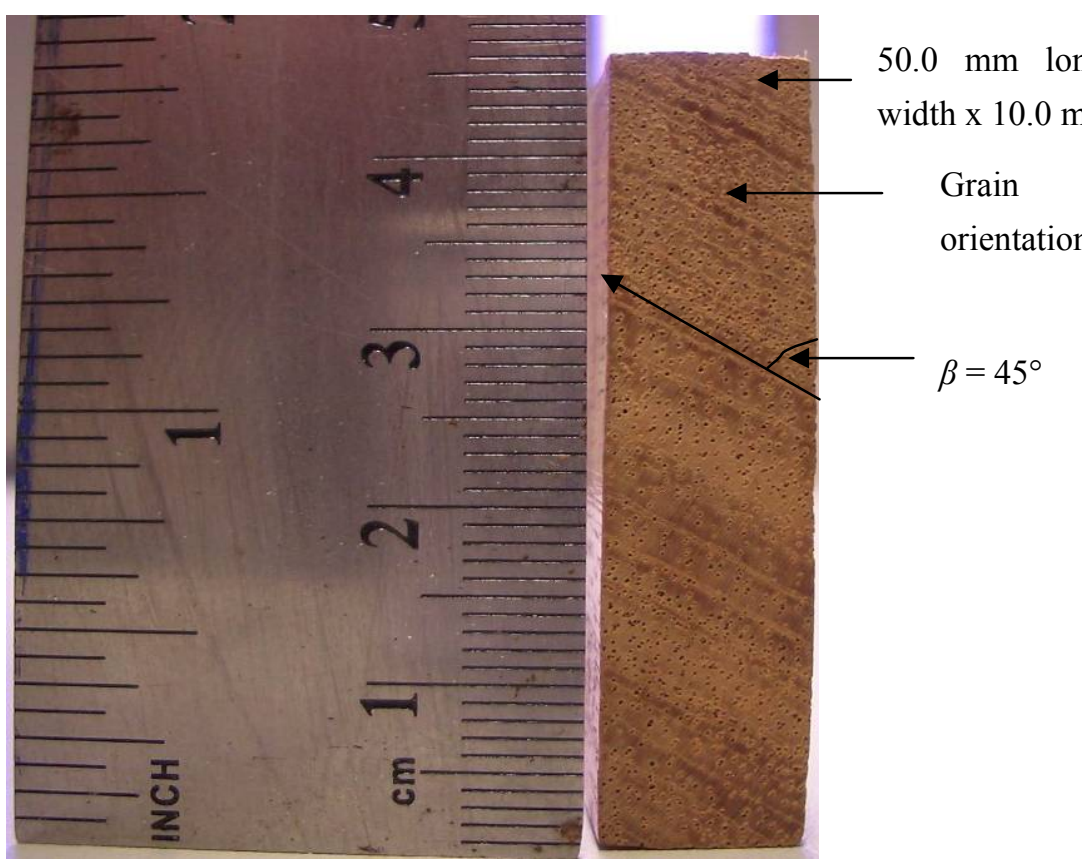

Figure 2. Photograph image showing sample preparing for SAXS test, the sample was cut as fibre orientation $\beta=$ $45^{\circ}$

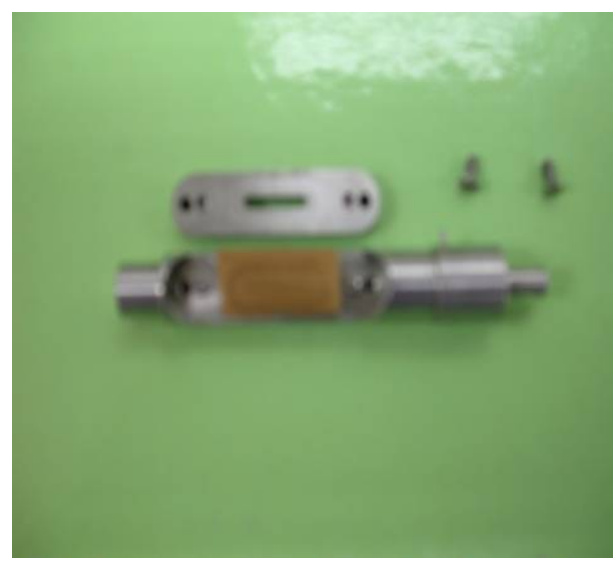

(a)

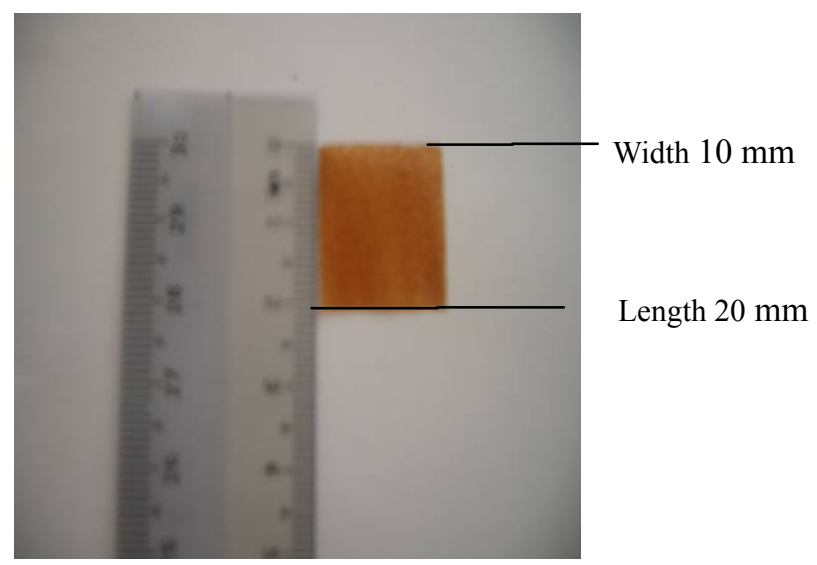

(b)

Figure 3. (a) Sample holder of SAXS machine with wood strip. (b) Wood strip 


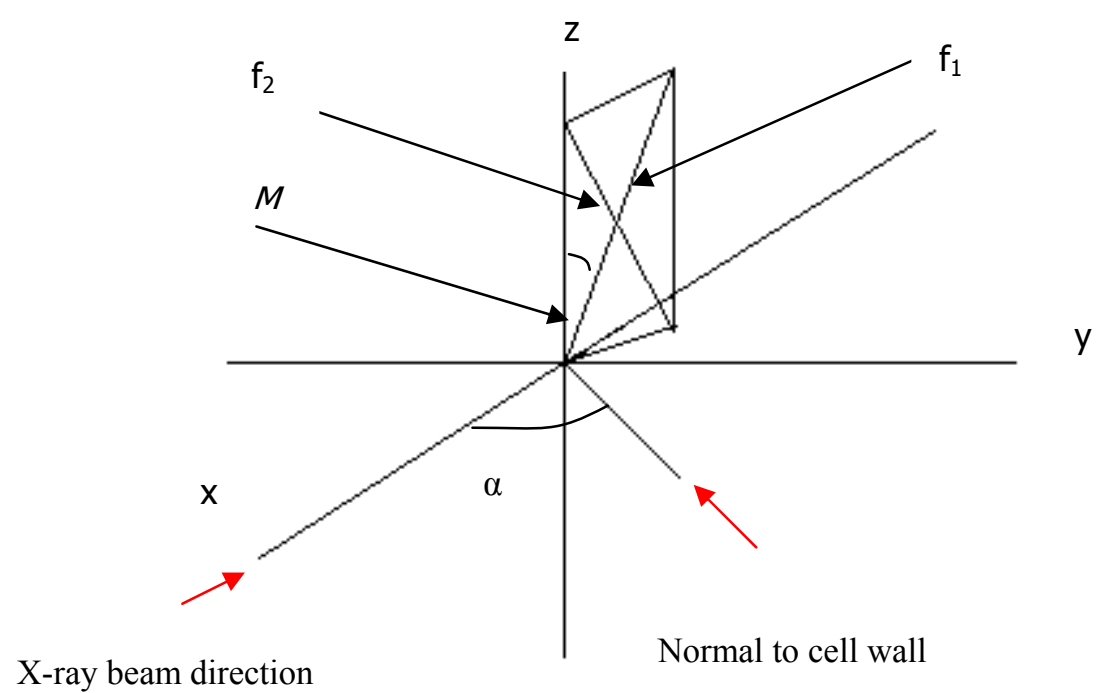

Figure 4. Diagram showing the relationship between a cell wall, the two $\mathrm{S}_{2}$ microfibrils and the direction of the X-ray beam

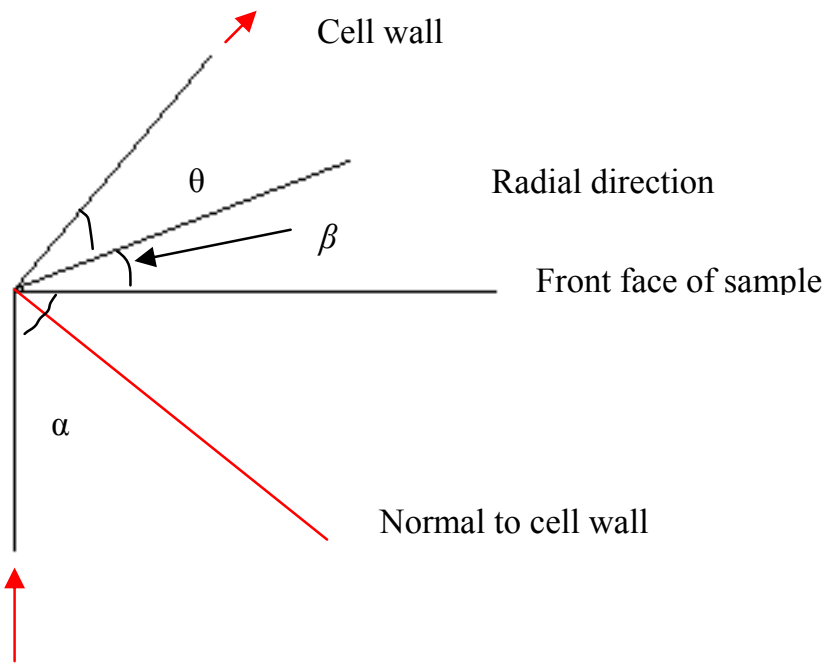

Direction of x-ray beam

Figure 5. Diagram showing the relation between front face of the thin sample, the radial direction $(\beta)$, the cell-wall direction $(\theta)$ and the direction of the X-ray beam normal to the face of the sample 


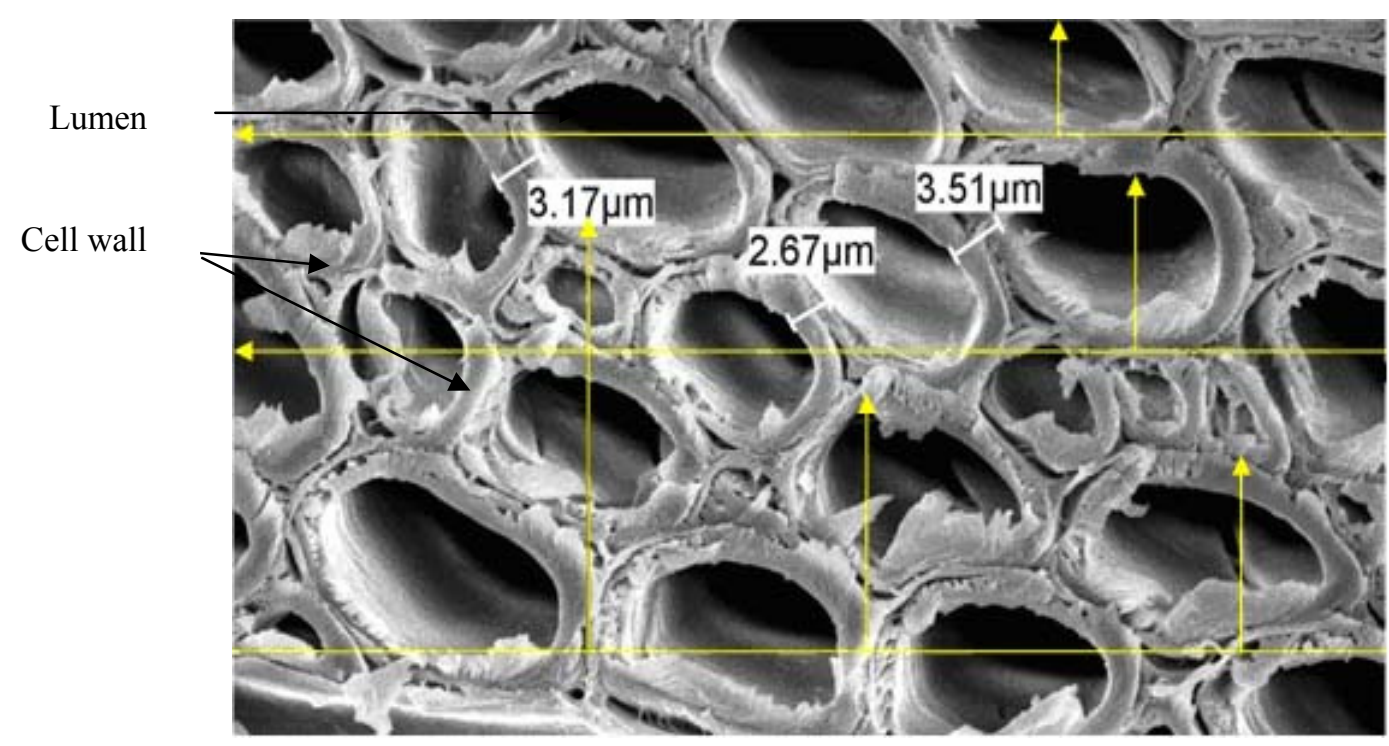

Figure 6. SEM micrograph at magnification X 2000, showing the shape of the real cell wall of Acacia mangium used for MFA estimation, sample taken from the pith region of 10 year-old tree

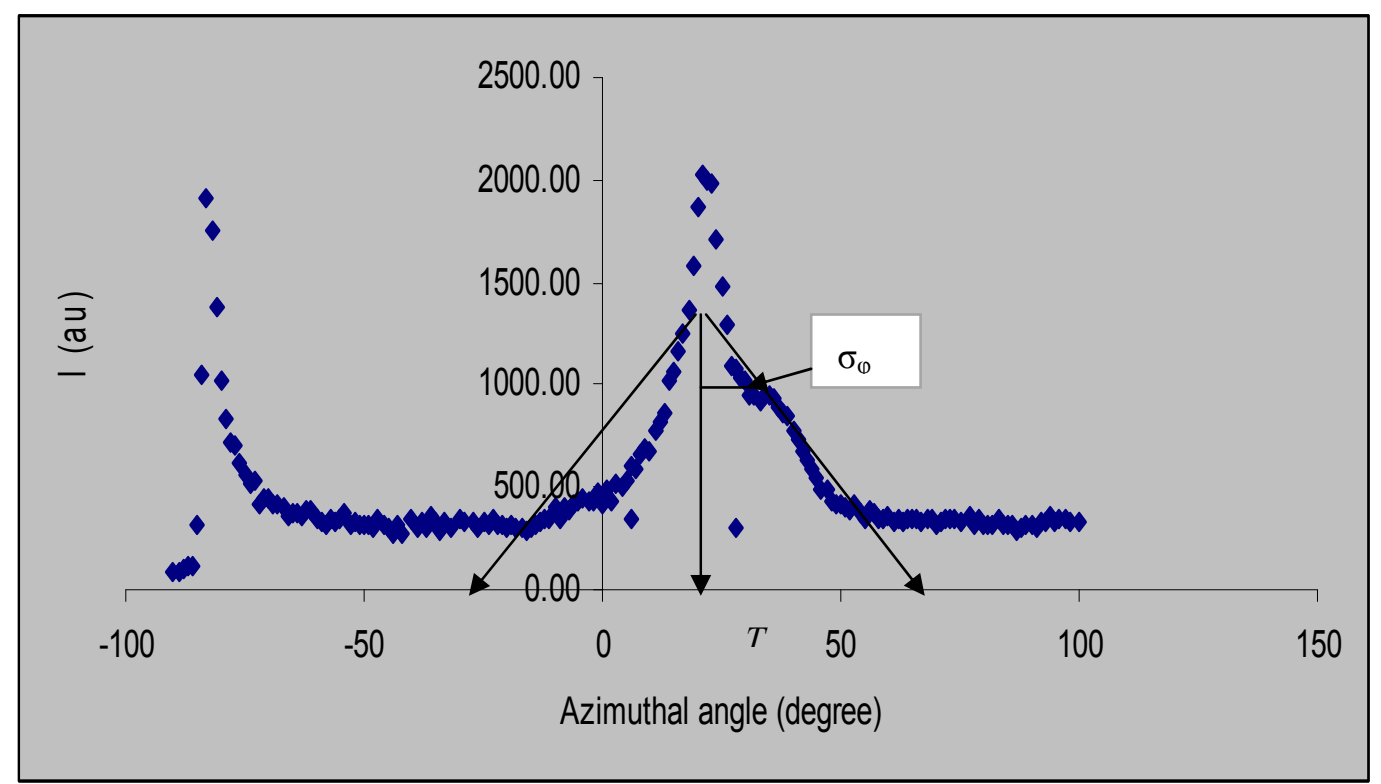

Figure 7. The intensity distribution for $\beta=45^{\circ}$ is plotted against azimuthal angle. MFA $=29.4^{\circ}$ and $\sigma_{\Phi}=9.8^{\circ}$ 


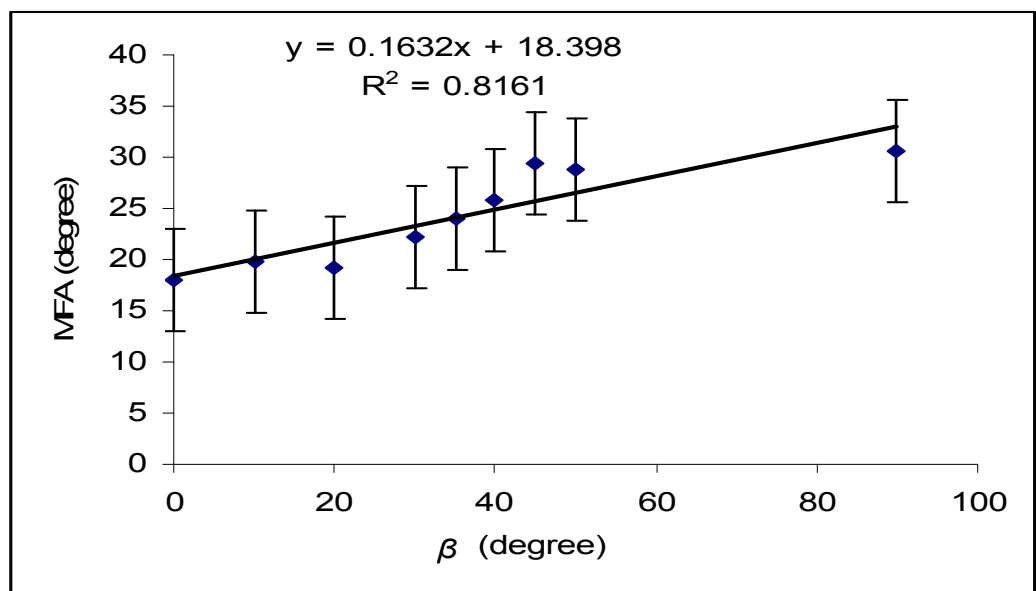

Figure 8. Variation of the measured MFA and the angle $\beta$ in Acacia mangium wood of 10-year-old

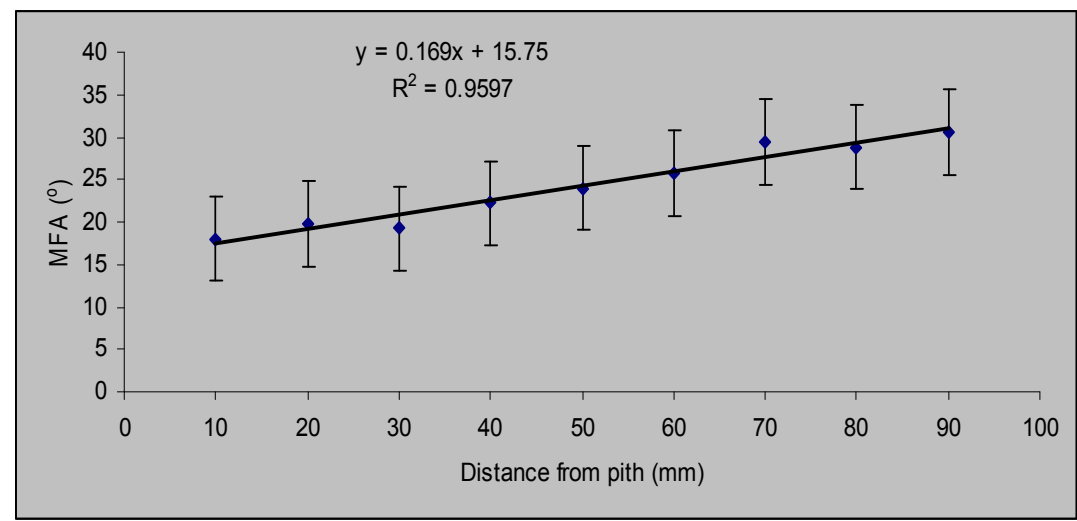

Figure 9. The relationship between measured MFA and the distance from pith to bark in Acacia mangium wood of 10 year-old 